\title{
Unusual photodermatosis with lichenoid eruption and apoptosis in a 33-year-old female
}

\author{
Jordan M. Montoya ${ }^{1}$, David J. DiCaudo ${ }^{1}$, Aaron R. Mangold ${ }^{1}$, David L. Swanson ${ }^{1}$
}

\begin{abstract}
We describe the clinical and dermoscopic features and histopathological findings in a case of a 33-year-old female patient with an adult-onset photodermatosis. This eruption was not typical of well-established photodermatoses due to its apoptotic keratinocytes. To our knowledge, this is the first report of these combined clinical and pathologic features.
\end{abstract}

Keywords: photodermatoses, hydroa, lichenoid eruption, photosensitive disorders

Received: 11 September 2018 | Returned for modification: 22 November 2018 | Accepted: 3 January 2019

\section{Introduction}

Photodermatoses are rashes that develop after sun exposure. Idiopathic photodermatoses unrelated to secondary causes are loosely classified into the following categories: polymorphic light eruption (PMLE), actinic prurigo, hydroa vacciniforme (HV), chronic actinic dermatitis, and solar urticaria. The exact pathomechanism of many of these skin reactions remains unknown. Clinical recognition of the lesions along with phototesting and histopathological findings are essential in establishing the diagnosis among idiopathic photodermatoses. Herein we describe a case and dermoscopic findings of an unusual photodermatosis with lichenoid pathology and necrotic keratinocytes that was diagnosed by clinical features, dermoscopic findings, and histopathological findings.

\section{Case report}

A 33-year-old Native American woman presented with a seasonal rash on her arms that first appeared in her late teens. The rash began in the summertime and erupted several hours after sun exposure. The rash presented as small pruritic erythematous papules on her face, ears, and arms; the trunk and lower extremities were spared. The rash completely resolved in the winter with no evidence of scarring. Serological tests for lupus and rheumatoid arthritis were negative. She achieved partial relief with triamcinolone and diphenhydramine.

Physical examination showed numerous monomorphic, pink papules on the dorsal forearms (Fig. 1) without scaling, erosion, or blistering. The upper arms and dorsal hands were unaffected, as were the back, lower extremities, and ears. When examined with contact polarized dermoscopy, the papules were white and poorly marginated (Fig. 2). Contact non-polarized dermoscopy showed poorly marginated papules, some of which showed course granularity and white scale (Fig. 3). There was no evidence of scarring.

A punch biopsy specimen from the forearm showed intra-epidermal vesicles with focal epidermal necrosis and mild to moderate perivascular lymphocytic dermal inflammatory infiltrate. (Fig 4). There were numerous necrotic keratinocytes with overlying parakeratosis present in the epidermis. The lymphocytic inflam- matory infiltrate consisted mostly of CD3-positive T-cells, with smaller populations of CD4- and CD8-positive cells. The CD56 immunostain and in situ hybridization for Epstein-Barr virus were negative.

The patient was prescribed triamcinolone for active flares. She was encouraged to use oral Polypodium leucotomos, zinc/ titanium-based sunscreens, and barrier clothing sun protection for prevention.

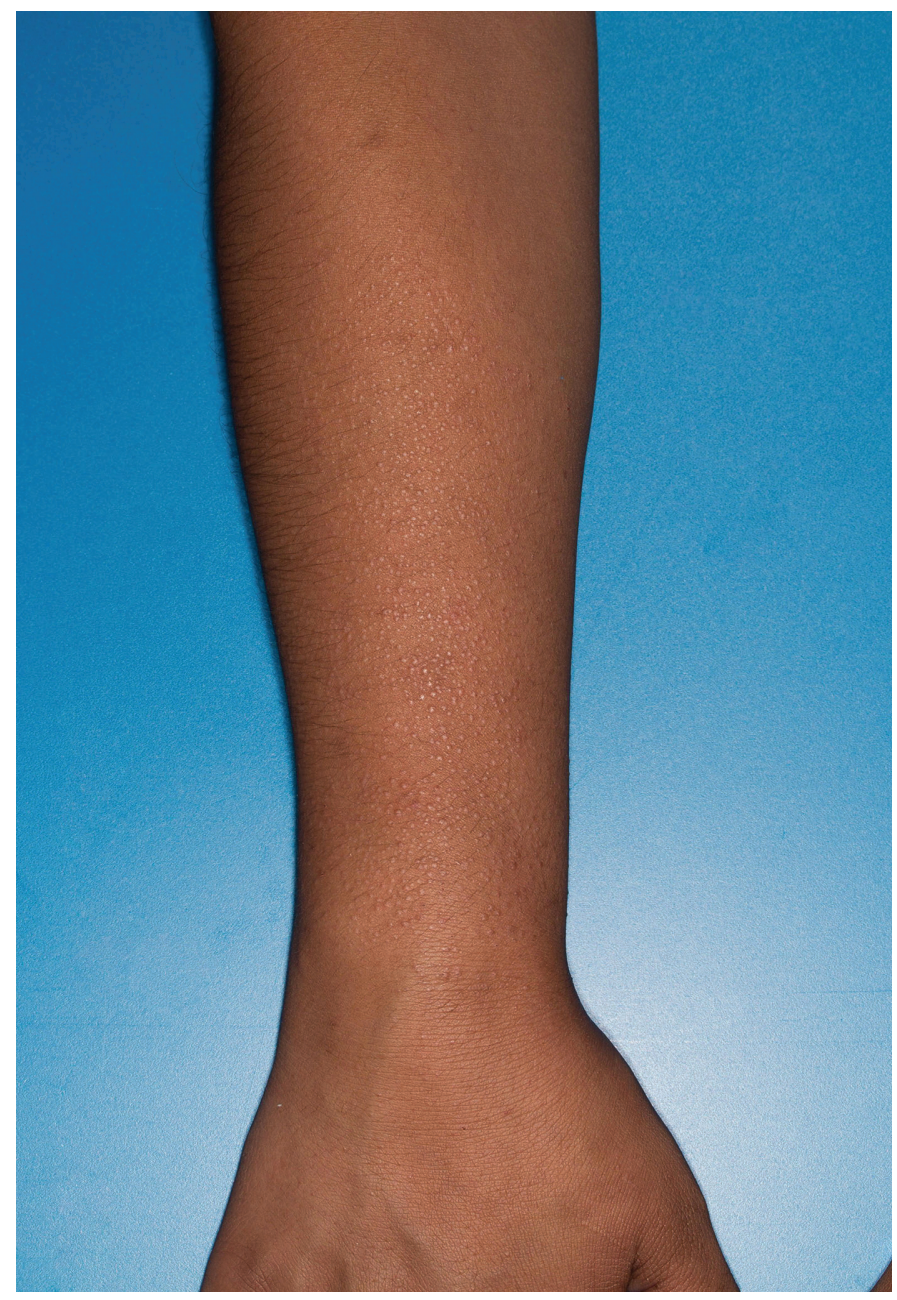

Figure 1 | Numerous monomorphic, pink papules on the dorsal forearm. 


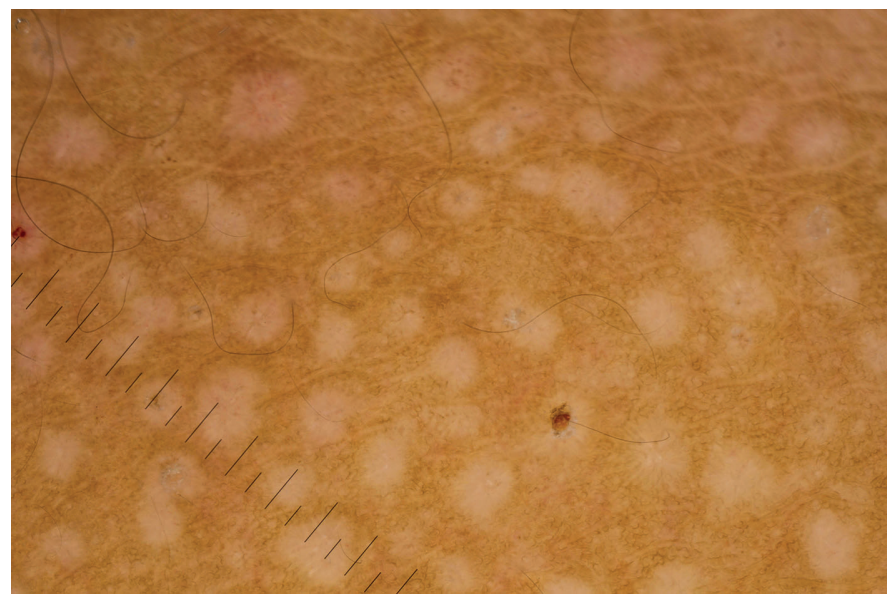

Figure 2 | Contact polarized dermoscopy of poorly marginated, white macules, some of which displayed course granularity.

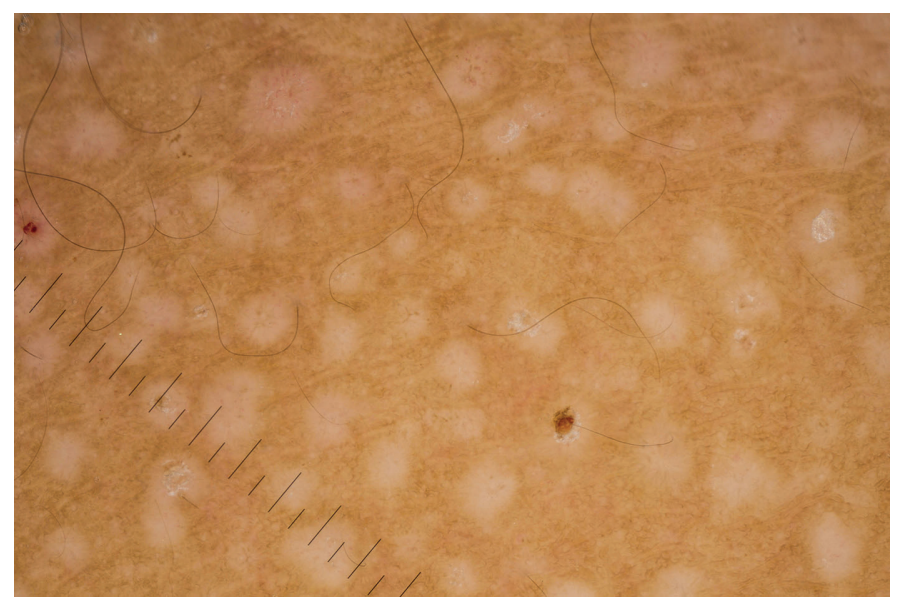

Figure 3 | Contact nonpolarized dermoscopy of poorly marginated macules with course granulations and white scales.

\section{Discussion}

This case defied a unifying diagnosis from clinical and histopathology findings. Hydroa aestivale (HA) was initially felt to be the most likely diagnosis. HA clinically presents with papules, macules, and vesicles that appear 1 to 2 hours after exposure to sunlight, ultraviolet light, or visible light. The rash is limited to sun-exposed skin, and most intensely occurs on the ears, neck, and arms. It is characterized by erythema of the exposed field, accompanied by macules, papules, and vesicles. The vesicles are typically associated with a burning sensation or pruritus. HA usually does not scar and is familial in up to $10 \%$ of cases. It most frequently presents in childhood, and it resolves by the onset of

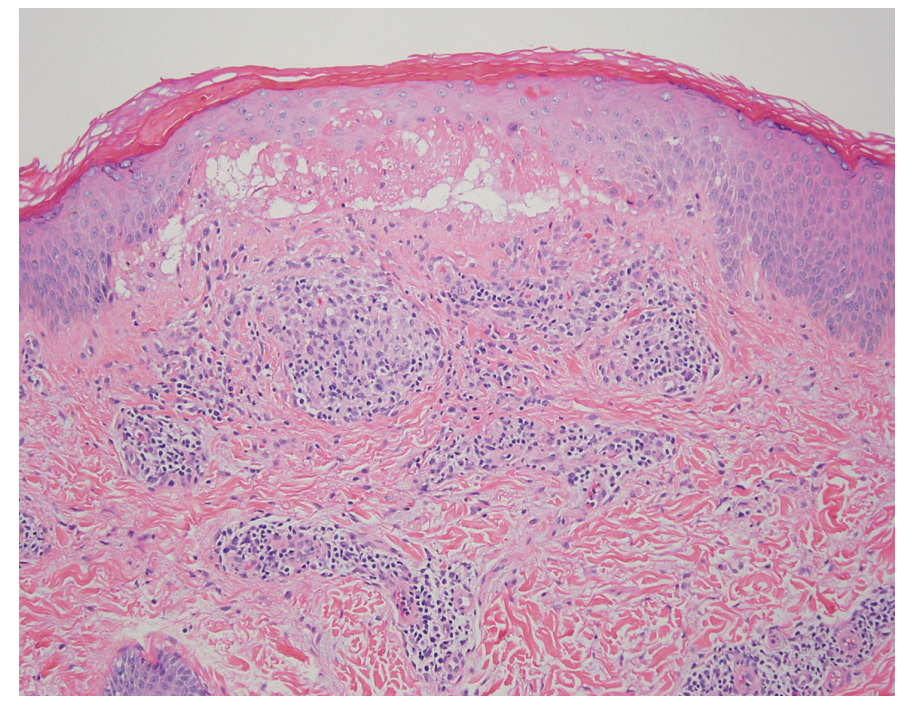

Figure 4 | Intraepidermal vesicle with focal epidermal necrosis and perivascular lymphocytic dermal inflammation (hematoxylin-eosin; original magnification $100 \times)$.

puberty or the late teens $(2,3)$. This is inconsistent with our case, in which the photodermatoses presented after the onset of puberty. The histopathology is consistent with HA. However, the lack of reports on $\mathrm{HA}$ as a confirmed, separate diagnosis from $\mathrm{HV}$ and the inconsistent clinical picture suggest that this is not HA.

The differential diagnosis of HA includes other photosensitive disorders that present with lesions on the skin after visible light exposure, such as HV, pinpoint PMLE, lichen nitidus, and actinic prurigo. HV was ruled out on clinical morphological differences and the absence of crusts and varioliform scarring after sun exposure that are typically seen with and without dermoscopy (5). It is controversial whether HA is a distinct entity from HV (4). Lichen nitidus presents with pink macules as seen in our case; however, the dermoscopic appearance is one of elevated, shiny macules with radial ridges, and a surrounding reddish vascular network (6). The histopathology of lichen nitidus is distinctive, and it differs markedly from this case (7). PMLE heals without scarring but lacks necrotic keratinocytes (8). Actinic prurigo manifests as a photodermatosis of sun-exposed areas of the skin, but its histopathologic characteristics are nonspecific and do not include necrotic keratinocytes (9). There are no reports at this time of the dermoscopic features of HA, HV, PMLE, and actinic prurigo.

In summary, we present a case and dermoscopic findings for a 33-year-old woman whose clinical and histopathologic features were not consistent with HA, HV, lichen nitidus, PMLE, and actinic prurigo. We are soliciting similar case presentations.

\section{References}

1. Redeker AG, Bronow RS. Erythropoietic protoporphyria presenting as hydroa aestivale. Arch Dermatol. 1964;89:104-9.

2. Wheeler CE, Cawley EP, Whitemore CW. Hydroa aestivale in identical twins. Arch Dermatol. 1960;82:590-4.

3. Qian G, Wang H, Wu J, Meng Z, Xiao C. Different dermoscopic patterns of palmoplantar and nonpalmoplantar lichen nitidus. J Am Acad Dermatol. 2015;73:101-3.

4. Park HY, Park JH, Lee KT, Lee DY, Lee JH, Lee ES, et al. A case of hydroa vacciniforme. Ann Dermatol. 2010;22:312-5.

5. Eramo LR, Garden J, Esterly NB. Hydroa vacciniforme: diagnosis by repetitive ultraviolet-A phototesting. Arch Dermatol. 1986;122:1310-3.

6. Wheeler CE, Cawley EP, Whitemore CW. Hydroa aestivale in identical twins. Arch Dermatol. 1960;82:590-4.

7. Leenutaphong V, Hölzle E, Plewig G. Pathogenesis and classification of solar urticaria: a new concept. J Am Acad Dermatol. 1989;21:237-40.

8. Chiam, LYT, Wei-Sheng C. Pinpoint papular polymorphous light eruption in Asian skin: a variant in darker-skinned individuals. Photodermatol Photoimmunol Photomed. 2009;25:71-4.

9. Hojyo-Tomoka MT, Vega-Memije ME, Cortes-Franco R, Dominguez-Soto L. Diagnosis and treatment of actinic prurigo. Dermatol Ther. 2003;16:40-4. 